\title{
XÁC ĐỊNH KHỐI LỰ̛̣NG HỢP LÝ CỦA CẦN TRỤC CÓ TẦM RộNG
}

\author{
NGUYẼ̃N DANH SƠN \\ Trưòng Đại học Công nghiệp thành phố Hồ Chí Minh; \\ nguyendanhson@iuh.edu.vn
}

Tóm tắt. Khối lượng máy là một trong những thông số quan trọng của máy trục, xác lập giá thành sản xuất của máy. Việc xác định khối lượng hợp lý của máy trục là một vấn đề quan trọng và cần thiết để giảm giá thành máy. Bài báo đưa ra các công thức giải tích để xác định khối lượng hợp lý của máy trục. Chúng có thể được sử dụng khi thực hiện công việc thiết kế,khi xác định hiệu quả các cần trục và tối ưu hóa chúng.

Từ khóa. Cầu trục, cổng trục, khối lượng hợp lý.

\section{DETERMINATION OF RATIONAL MASS OF SPAN CRANE}

\begin{abstract}
Mass is one of important parameters of hoisting machinery.This confirms manufacturer price of machine.The determination of rational mass of crane is one important and necessary problem for reduction of machine price. The paper come up with analytic formulas to determine rational mass of crane.They can be used in disign, in determination of machine effect and in optimization.
\end{abstract}

Keywords. Bridge Crane, Gantry Crane, rational mass.

\section{1. ĐẶT VẤN ĐỀ}

Việc chế tạo các loại máy trục có tầm rộng ( cầu trục, cổng trục) trong nước là vấn đề quan trọng, góp phần đáp ứng việc cơ giới hóa các quá trình sản xuất, xây dựng nhất là khi nâng chuyển các vật nặng.Bên cạnh đó còn tiết kiệm ngoại tệ nhập máy, tạo công ăn việc làm cho người lao động và nâng cao vai trò của cán bộ kỹ thuật và rút ngắn thời gian đầu tư thiểt bị cho các công trình.Các loại máy này nếu nhập ngoại hoàn toàn thì giá thành của máy được tính theo khối lượng máy với giá là 20 US\$/1 kilôgam.Tính ra thì giá thành máy rất cao vì kết cấu thép của máy chiếm gần $70 \%$ khối lượng máy[6].

Trong khi đó nểu một máy có cùng công dụng và các thông số kỹ thuật được chế tạo trong nước thì chỉ tốn có 2 US\$ mà thôi [1]. Như vậy, nếu cần thiết phải mua máy từ nước ngoài thì ta chỉ nên đặt mua bộ máy nâng, còn lại các cụm máy khác và kết cấu thép thì có thể hoàn toàn chế tạo trong nước với giá thành rẻ hơn và nhanh chóng hơn. Vậy thì vấn đề được đặt ra sẽ góp phần giúp cho việc sản suất các máy trục tại trong nước được tốt hơn và kinh tế hơn.

\section{GIẢI QUYẾT VẤN ĐỀ}

Kết cấu thép của máy trục có dầm dạng hộp bao gồm dầm chính và dầm bên. Khối lượng của dầm chính đóng vai trò chủ yếu.Việc xác định khối lượng hợp lý của máy trục là một vấn đề cần thiết và cấp bách nhằm giảm giá thành máy.

Hiện nay trên thế giới và trong nước việc xác định khối lượng hợp lý của một loại cần trục cụ thể chưa có tác giả giả nào nghiên cứu đến. Tuy nhiên, việc nghiên cứu về kết cấu kim loại máy trục nói chung cũng đã được đề cập đến như trong [2]. Giáo sư Tiến sỹ Nga Gôbe đã đưa ra cách xác định các kích thước của dầm tổ hợp như chiều cao của dầm, kích thước thành dầm, kích thước tấm biên bằng các công thức giải tích. Trong công trình của mình [3]. Giáo sư Tiến sỹ Alếchxandrov khi nghiên cứu về kết cấu thép của cầu trục đã đưa ra công thức thực nghiệm xác định chiều cao của dầm cầu trục có tiết diện hình hộp $h_{d}=(1 / 16-1 / 20) L$, trong đó $\mathrm{L}$ là tầm rộng của cầu trục. Cũng trong công trình này Giáo sư Tiến 
sỹ Alếchxandrov còn đưa ra được đồ thị để xác định khối lượng của một nửa dầm cầu trục ứng với tầm rộng của cầu trục. Trong nước ta thì các giáo trình dùng để giảng dạy môn học Máy nâng chuyển của giáo sư Tiến sỹ đào Trọng Thường [4], Máy trục vận chuyển của PGS. TS. Nguyễn Văn Hợp [5], Kỹ thuật nâng chuyển [6], Tính toán máy trục của PGS. TS. Huỳnh văn Hoàng [7] cũng không có đi sâu về tính toán kết cấu thép của các loại máy trục có dầm hộp và cũng đưa ra một số công thức kinh nghiệm tương tự như của các giáo sư Nga.

Như vậy trong bài báo này chúng tôi đề xuất việc xác định khối lượng hợp lý cho loại cần trục có tầm rộng thông qua việc xác định khối lượng cuả dầm chính để làm cơ sở cho việc xác định giá thành của máy.

Chúng tôi giải quyết việc này như sau:

Mô tả khái quát Kết cấu thép của câù trục (cổng trục) và dầm chính của nó rồi đưa ra sơ đồ tính toán tiết diện của dầm chính.

Nghiên cứu những công trình có liên quan tới vấn đề đặt ra của các giáo sư Nga về mặt lý thuyết, những công trình thực nghiệm vả một số công thức thực nghiệm để xem áp dụng trong khoảng giá trị nào là thich hợp nhất.

Thống kê khối lượng của một số cầu trục và cổng trục do chính mình thiết kế, chế tạo trong nước và một số đơn vị khác đã chế tạo và lắp đặt những máy trục của nước ngoài tại Việt Nam (TP.HCM và một số tỉnh phía nam) để làm số liệu so sánh.

Xác định khối lượng hợp lý của dầm chính bằng cách tính toán trên cơ sở kiến thức Sức bền vật liêu.

Đưa ra những giải thích, biện luận cần thiết để làm sáng tỏ vấn đề nghiên cứu.

\subsection{Mô tả khái quát Kết cấu thép của câù truc và dầm chính và sơ đồ tính toán tiết diện của dầm chính}

Kết cấu thép của cầu trục được thể hiện trên hình chiếu bằng dưới đây (xem hình 1) gồm hai dầm chính và hai dầm bên. Hai dầm chính được liên kết chặt với hai dầm bên bằng mối ghép hàn hoặc mối ghép bulông. Trên hình vẽ thì kích thước $\mathrm{L}_{\mathrm{k}}$ là tầm rộng của cầu trục và là một trong các thông số cơ bản của nó.

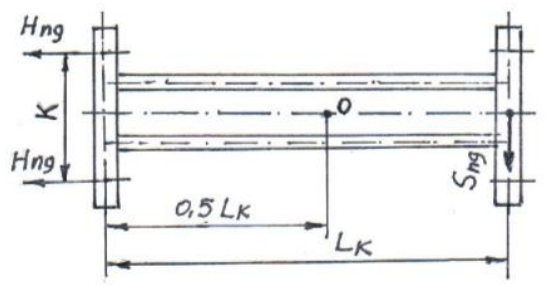

Hình 1 . Sơ đồ kết cấu thép của cầu trục.

Qua nghiên cứu về các loại dầm chính của cầu trục và cổng trục ta thấy rằng loại dầm chính hình thang là hợp lý và phổ biến nhất (xem hình chiếu chính của dầm chính trên hình 2).

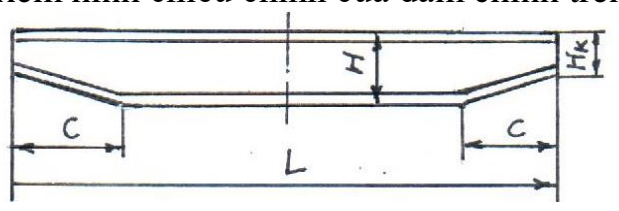

Hình 2. Dầm chính hình thang.

Tiết diện ngang của dầm chính được thể hiện trong hình 3 , gồm một bản cánh trên, một bản cách dưới có chiều dày $\delta_{1}$, hai thành đứng có chiều dày $\delta_{2}$ được liên kết với nhau bằng phương pháp hàn hoặc bằng mối ghép bulông. Bản cánh trên và bản cánh dưới có phần chìa hai bên như trên hình 3.a hoặc không có phần chìa hai bên như trên hình $3 \mathrm{~b}$ và hình $3 \mathrm{c}$. Các hình vẽ này cũng là sơ đồ tính toán mà chúng tôi sẽ sử dụng ở dưới đây 


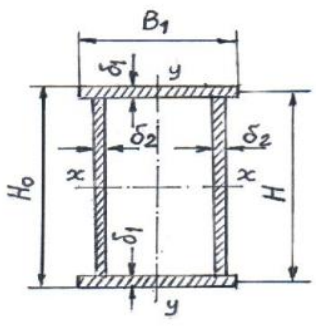

a)

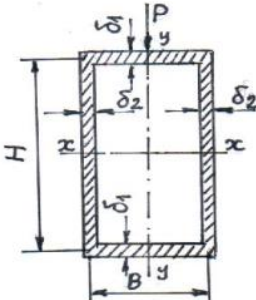

b)

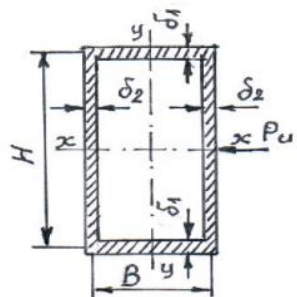

c)

Hình 3. Sơ đồ tính toán các dầm.

\subsection{Nghiên cứu những công trình có liên quan}

Từ công trình [2] của Giáo sư Tiến sỹ Gôbe ta nhận thấy rằng khối lượng của dầm chính phụ thuộc vào nhiều thông số như chiều cao của dầm, kích thước của thành đứng và kích thước các bản cánh trên và dưới. Trong công trình [3] Giáo sư tiến sỹ Alếchxanđrov đưa ra công thức thực nghiệm xác định chiều cao của dầm $h_{\mathrm{d}}=(1 / 16-1 / 20) \mathrm{L}$ và đồ thị xác định khối lượng của một nửa dầm cầu trục ứng với tầm rộng của cầu trục. Từ hai công trình trên chúng tôi nhận thấy rằng công trình [2] cho phép bổ sung về mặt lý thuyết tính toán cho một loại máy cụ thể. Công trình [3] cho ta xác định được sơ bộ khối lượng của dầm. Khối lượng máy tính theo công trình này có thể lớn hơn thực tế $10-20 \%$ theo phương pháp tính toán chính xác.

Chúng tôi nhận thấy rằng việc xác định khối lượng hợp lý của cần trục phải xuất phát từ việc xác định tỷ số cơ bản của các kích thước dầm chính. Khi tính toán thiết kế dầm chính của máy trục phải xác định giá trị cần thiết của các mô men chống uốn tại tiết diện nguy hiểm theo phương đứng và phương ngang. Để đảm bảo giá trị của các mômen chống uốn có thể có nhiều giá trị kích thước của các bản cánh và các thành đứng.Vậy thì vấn đề xác định kích thước hợp lý của các bản cánh và các thành đứng là cần thiết. Khi thiết kế thường thì người ta lấy tỷ số các kích thước phản ánh được kinh nghiệm thiết kế, chế tạo và sử dụng cần trục. Ở các dầm dùng làm kết cấu thép của cần trục thì chiều dày của các bản cánh ( trên và dưới) và chiều dày của các thành đứng thì nhỏ hơn so với các kích thước của tiết diện ngang của dầm, cho nên những dầm như thế được xem như là kết cấu có thành mỏng.

Chiều cao lớn nhất của dầm $\mathrm{h}_{\max }$ được giới hạn bởi các điều kiện tối ưu hóa để nhận được khối lượng dầm là nhỏ nhất $\mathrm{G}_{\mathrm{min}}$, còn chiều cao nhỏ nhất của dầm được giới hạn bởi điều kiện độ võng của dầm hay thời gian tắt dần dao động của dầm.

Chiều dày của thành đứng $\delta_{2}$ (xem hình $1 . \mathrm{a}$ ) được xác định từ điều kiện ổn định và điều kiện bền của nó.Chiều dày nhỏ nhất của thành đứng nên lấy bằng $6 \mathrm{~mm}$, còn khi cần trục làm việc ở môi trường có độ ăn mòn cao thì nên lấy bằng $8 \mathrm{~mm}$ [8].

\subsection{Thống kê khối lượng của một số cầu trục và cổng trục}

Bảng 1.So sánh khối lượng một số cầu trục.

\begin{tabular}{|l|l|l|l|l|l|}
\hline TT & $\begin{array}{l}\text { Trọng } \\
\text { tải nâng } \\
\text { Q (Tấn) }\end{array}$ & $\begin{array}{l}\text { Tầm rộng } \\
\mathrm{L}_{\mathrm{k}} \text { (Mét) }\end{array}$ & $\begin{array}{l}\text { Khối lượng cầu trục } \\
\text { của Liên xô cũ nhập về } \\
\text { theo thống kê } \\
\text { m (Tấn) }\end{array}$ & $\begin{array}{l}\text { Khối lượng cầu trục được chế } \\
\text { tạo trong nước } \\
\text { m (Tấn) }\end{array}$ & $\begin{array}{l}\text { Chênh lệch khối } \\
\text { lượng }(\%)\end{array}$ \\
\hline 1 & 50 & 23 & 30 & 25 & 16,6 \\
\hline 2 & 50 & 20 & 20 & 17 & 15 \\
\hline 3 & 30 & 20 & 20 & 17 & 15 \\
\hline 4 & 20 & 23 & 22 & 19 & 13,6 \\
\hline 5 & 15 & 20 & 14 & 12 & 14,2 \\
\hline 6 & 10 & 20 & 12 & 10 & 16,6 \\
\hline 7 & 5 & 20 & 6 & 5 & 16 \\
\hline
\end{tabular}

So sánh khối lượng của một số cầu trục được chế tạo trong nước do Bộ môn Máy xây dựng và Nâng chuyển Trường ĐH Bách khoa TP. HCM chế tạo với khối lượng của một số cầu trục của nước ngoài 
(Liên Xô cũ, đức, Thụy sỹ) được đưa vào bảng 1.Theo dõi một số cầu trục và cổng trục được chế tạo và lắp đặt tại thành phố Hồ Chí Minh và một số tỉnh phía Nam của công ty Máy trục và Thang máy Quảng Liên Đài Loan), Công ty máy trục Kone crane (Thụy sỹ), Công ty Máy trục và Thang máy Hòa bình (Việt nam),công ty TNHH Phan Vũ Việt nam)... Chúng tôi nhận thấy rằng với cùng một trọng tải nâng và tầm rộng của cầu trục hai dầm có tiết diện hình hộp thì khối lượng của các cần trục xuất xứ từ châu Âu thì tương đương với khối lượng các cần trục của Liên Xô cũ còn các cần trục xuất xứ từ các nước Châu Á thì có khối giảm hơn khoảng từ 5-7\%.Từ bảng 1 ta nhận thấy rằng với sơ đồ kết cấu dầm chính truyền thống có tiết diện hình hộp với phần chìa hai bên và khi đã đảm bảo về độ bền và độ cứng vững của cầu trục thì với cùng một trọng tải nâng và cùng một tầm rộng có sự chênh lệch về khối lượng từ 13,6 đến $16,6 \%$. Sự giảm khối lượng này sẽ dẫn tới giảm đáng kể giá thành của máy.

\subsection{Xác định khối lượng hợp lý của dầm chính}

Các kết cấu được coi là tối ưu là những kết cấu mà khi làm việc tin cậy có tổng giá thành chế tạo và sử dụng là nhỏ nhất. Gía thành kết cấu được xác định chủ yếu bằng khối lượng của nó (giá vật liệu chiếm gần $70 \%$ tổng giá thành của kết cấu thép). Có thể lấy khối lượng kết cấu làm chuẩn tối ưu cơ bản của cần trục.

Chiều cao tối ưu của dầm hộp được xác định bằng cách tính bền uốn dầm theo sơ đồ tính toán ở hình 3 khi đã xác định được khối lượng đơn vị $\mathrm{g}$ trên một mét dài của dầm rồi đạo hàm biểu thức giá trị của $\mathrm{g}$ theo $\mathrm{H}$ và cho đạo hàm bằng 0 ta được

$$
H_{t . u}=\sqrt{\frac{3 w_{x}}{2 \delta_{2}}}
$$

Trong đó: $\mathrm{w}_{\mathrm{x}}-$ mô men chống uốn của tiết diện dầm, $\delta_{2}-$ chiều dày thành đứng của dầm.

Ta thấy rằng nếu có sự sai lệch của chiều cao dầm so với giá trị tối ưu là $20 \%$ thì khối lượng của dầm chỉ thay đổi $2,5 \%$, nên chiều cao của dầm có thể lấy nhỏ hơn giá trị tối ưu một ít với điều kiện là phải đảm bảo độ cứng tĩnh và độ cứng động của dầm. Khi tính bền uốn dầm trong một mặt phẳng (mặt phẳng đứng) thì mô men chống uốn cần thiết của tiết diện là:

$$
W_{x} \geq \frac{M}{[\sigma]},
$$

Trong đó: $\mathrm{M}$-mô men uốn, $[\sigma]$ - ứng suất uốn cho phép.

Khi biết chiều cao $\mathrm{H}$ của dầm thì mô men quán tính của dầm là:

$$
\mathrm{J}_{\mathrm{x}}=\mathrm{w}_{\mathrm{x}} \cdot \mathrm{y}
$$

Trong đó: $\mathrm{y}-$ khoảng cách từ trục trung hòa đến thớ ngoài cùng của dầm.

Khi tính uốn dầm chính trong mặt phẳng đứng thì tiết diện dầm có 2 trục đối xứng và chiều cao $\mathrm{H}$ thì:

$$
\mathrm{y} \approx \mathrm{H} / 2 \text { và } \mathrm{J}_{\mathrm{x}} \approx \mathrm{W}_{\mathrm{x}} \cdot \mathrm{H} / 2,
$$

Mô men quán tính của tiết diện hai thành đứng có chiều dày $\delta_{2}$ được xác định theo công thức:

$$
\mathrm{J}_{2 \mathrm{x}}=\delta_{2} \cdot \mathrm{H}^{3} / 6 \text {, }
$$

Mô men quán tính của hai bản cánh có chiều dày $\delta_{1}$ so với đường trục ngang của dầm ( với điều kiện bỏ qua các mô men quán tính của các tiết diện bản cánh so với đường trục trung hòa riêng của chúng) được xác định theo công thức:

Trong đó: F- diện tích tiết diện của một bản cánh.

$$
\mathrm{J}_{1 \mathrm{x}} \approx 2 \mathrm{~F}_{1}(\mathrm{H} / 2)^{2},
$$

vì $\mathrm{J}_{1 \mathrm{x}}=\mathrm{J}_{\mathrm{x}}-\mathrm{J}_{2 \mathrm{x}}$ nên diện tích cần thiết là:

$$
\mathrm{F}_{1}=2\left(\mathrm{~J}_{\mathrm{x}}-\mathrm{J}_{2 \mathrm{x}}\right) / \mathrm{H}^{2}
$$

Đối với dầm có phần chìa hai bên của bản cánh ( xem hình 1 .a) có chiều rộng chung là $\mathrm{B}_{1}$ thì chiều dày của bản cánh được xác định theo công thức:

$$
\delta_{1}=\mathrm{F}_{1} / \mathrm{B}_{1}=2\left(\mathrm{~J}_{\mathrm{x}}-\mathrm{J}_{2 \mathrm{x}}\right) / \mathrm{H}^{2} \cdot \mathrm{B}
$$

Đối với dầm không có phần chìa hai bên của bản cánh hoặc khi bỏ qua chiều rộng các phần chìa của bản cánh tức là $\mathrm{B}_{1}=\mathrm{B}$, khi đó:

$$
\delta_{1}=2\left(\mathrm{~J}_{\mathrm{x}}-\mathrm{J}_{2 \mathrm{x}}\right) / \mathrm{H}^{2} . \mathrm{B}
$$


Khi tính bền uốn dầm trong hai mặt phẳng cần phải tính mô men chống uốn của tiết diện dầm đối với đường trục ngang và đường trục đứng, được xác định theo phép tính bền các tổ hợp tải trọng IIa và IIb theo các công thức:

$$
\left(\mathrm{M}_{\mathrm{x}}\right)_{\mathrm{IIa}} / \mathrm{W}_{\mathrm{x}}=[\sigma] ; \quad\left(\mathrm{M}_{\mathrm{x}}\right)_{\mathrm{IIb}} / \mathrm{W}_{\mathrm{x}}+\left(\mathrm{M}_{\mathrm{y}}\right)_{\mathrm{IIb}} / \mathrm{W}_{\mathrm{y}}=[\sigma],
$$

trong các công thức này: $\mathrm{M}_{\mathrm{x}}$ và $\mathrm{M}_{\mathrm{y}}$ - các mô men uốn trong mặt phẳng ngang và trong mặt phẳng đứng, ngoài ra mô men $\left(\mathrm{M}_{\mathrm{x}}\right)_{\text {IIa }}$ không bằng mô men $\left(\mathrm{M}_{\mathrm{x}}\right)_{\mathrm{IIb}}$.

Đối với dầm có phần chìa hai bên của bản cánh với chiều rộng của bản cánh là $\mathrm{B}_{1}$ thì mô men chống uốn của tiết diện dầm đối với đường trục ngang và đường trục đứng được xác định theo công thức:

$$
\mathrm{W}_{\mathrm{x}}=\left(\mathrm{B}_{1} \cdot \delta_{1}+\delta_{2} \cdot \mathrm{H} / 3\right) \cdot \mathrm{H} ; \quad \mathrm{W}_{\mathrm{y}}=\mathrm{H} \cdot \delta_{2} \cdot \mathrm{B}_{1}+\delta_{1} \cdot \mathrm{B}_{1}^{3} / 3,
$$

Đối với dầm không có phần chìa hai bên của các bản cánh, khi $\mathrm{B}_{1}=\mathrm{B}$ thì:

$$
\mathrm{W}_{\mathrm{x}}=\left(\mathrm{B}_{1} \cdot \delta_{1}+\delta_{2} \cdot \mathrm{H} / 3\right) \cdot \mathrm{H} ; \mathrm{W}_{\mathrm{y}}=\left(\mathrm{H} \cdot \delta_{2}+\delta_{1} \cdot \mathrm{B} / 3\right) \mathrm{B},
$$

Đối với dầm có chiều cao tối ưu $\mathrm{H}_{\mathrm{t} . \mathrm{r}}$ thì diện tích tiết diện của một bản cánh là:

$$
\begin{aligned}
& \mathrm{F}_{1}=\mathrm{B} \cdot \delta_{1}=\mathrm{H}_{\mathrm{t} . \mathrm{r} \cdot} \cdot \delta_{2} / 2=\sqrt{\frac{3 w_{x}}{2 \delta_{2}}} \cdot \frac{\delta_{2}}{2}, \\
& B=\frac{3 w_{y}}{5 w_{x}} \sqrt{\frac{3 w_{x}}{2 \delta_{2}}},
\end{aligned}
$$

Giải kết hợp các phương trình (13) và (14) ta được:

$$
\delta_{1}=\frac{5 w_{x}}{6 w_{y}} \cdot \delta_{2}
$$

Vậy là ta đã xác định được các kích thước của bản cánh và thành đứng và khi có được các công thức này chúng ta dể dàng xác định được khối lượng hợp lý của dầm chính của cầu trục và đó là khối lượng của máy.

\section{5 Đưa ra những giải thích, biện luận cần thiết}

Để làm các bản cánh dầm cầu trục nên dùng thép tấm là thép cácbon có chiều dày tới $50 \mathrm{~mm}$ và thép hợp kim thấp có chiều dày tới $40 \mathrm{~mm}$. Nếu dầm không đáp ứng các điều kiện về độ cứng tĩnh và độ cứng động và thời gian tắt dần dao động thì chế tạo dầm có tiết diện thay đổi theo chiều dài của dầm. Khi đó sử dụng sự thay đổi chiều dày của bản cánh dưới hoặc chiều cao của dầm. Cũng có thể đồng thời thay đổi chiều dày của bản cánh dưới và chiều cao của dầm.

Trên hình 4 đưa ra bốn phương án chế tạo dầm chính của cầu trục với cùng một trọng tải nâng $\mathrm{Q}$ bằng 50 Tấn và tầm với $\mathrm{L}_{\mathrm{k}}$ bằng 34,5 mét và cùng một chiều cao của dầm, ở đây chỉ vẽ một phần đầu dầm bên trái vì là kết cấu đối xứng. Phương án I là dầm hình thang truyền thống, phương án II, III và IV là các phương án tăng chiều dày của bản cánh dưới bằng cách ốp thêm một hoặc hai tấm thép cho bản cánh dưới tăng độ dày.Sự so sánh cho thấy rằng dầm được chế tạo theo phương án III là có chi phí thấp nhất. So với dầm chính hình thang truyền thống ở phương án I thì nó có khối lượng giảm $24 \%$ và nhân công giảm $10 \%[8]$.

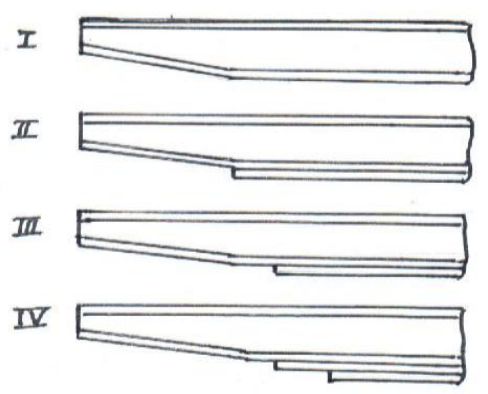

Hình 4. Các phương án chế tạo dầm cầu trục. 
Cũng trong công trình của mình[8] Tiến sỹ Sabasov chỉ ra rằng có thể sử dụng khối lượng tối thiểu của cầu trục làm chuẩn tối ưu của nó.

\section{KẾT LUẬN}

Sau nhiều năm trong làm công tác giảng dạy các môn học thuộc ngành Máy nâng chuyển và thực hiện thiết kế, sản xuất, chế tạo và lắp đặt các máy trục dạng dầm hộp tại Việt Nam, tác giả đã đưa ra được các công thức tích toán từ (1) đến (15) áp dụng từ môn học Sức bền vật liệu, để xác định khối lượng hợp lý của dầm chính của cầu trục có tiết diện hình hộp và đó chính là khối lượng của máy, điều này giúp cho việc giảm khối lượng máy và giá thành sản phẩm chế tạo trong nước. Nội dung đề tài nghiên cứu có thể giúp ích trong công việc thiết kế các máy trục kiểu này, ngoài ra còn cò thể áp dụng vào việc xác định hiệu quả của các cần trục và tối ưu hóa chúng.

\section{TÀI LIỆU THAM KHẢO}

1 - Nguyễn Danh Sơn(1996).Kinh nghiệm trong thiết kế, chế tạo cầu trục, cổng trục dạng dầm hộp trong nuớc, Tạp chí Lao động và xã hội số 2 , năm 1996.

2 - М. М. Гохберг(1980).Металлические конструкиии подъёмно-транспортных машин. Машиностроение.

3 - М.П.Александров ( 1981).Подъёмно-транспортные машины,,Высшая школа

4 - Đào Trọng Thường, Nguyễn Đăng Hiếu, Trần Doãn Thường, Võ Quang Phiên (1986). Máy nâng chuyển, Nhà xuất bản Khoa học kỹ thuật.

5 - Nguyễn văn Hợp, Phạm thị Nghĩa, Lê Thiện Thành(2000). Máy trục vận chuyển, Nhà xuất bản Giao thông vận tải.

6 - Huỳnh văn Hoàng, Trần thị Hồng, Nguyễn Hồng Ngân, Nguyễn Danh Sơn, Lê Hồng Sơn, Nguyễn Xuân Thiệp.Kỹ thuật nâng chuyển ( Tập 1), NXB Đại Học Quốc Gia TP. HCM.

7 - Huỳnh Văn Hoàng( 1986) Tính toán máy trục, Nhà xuất bản KHKT

8 - А.П.Шабашов, А.Г.Лысяков( 1980).Мостовые краны общего назначения,Машиностроение.

Ngày nhận bài: 04/01/2017

Ngày chấp nhận đăng: 28/05/2017 